\title{
SISTEM PENDUKUNG KEPUTUSAN DALAM MENENTUKAN PRIORITAS PENDISTRIBUSIAN DARAH MENERAPKAN METODE THE EXTENDED PROMETHEE II PADA KANTOR PALANG MERAH INDONESIA(PMI) MEDAN
} Rahma Dewi

\author{
Program Studi Teknik Informatika STMIK Budi Darma, Medan
}

\begin{abstract}
Abstrak
PMI (Palang Merah Indonesia) merupakan suatu organisasi perhimpunan nasional di Indonesia yang bergerak dalam bidang sosial kemanusiaan. Dalam melaksanakan tugasnya PMI tidak melakukan perbedaan tetapi lebih mengutamakan korban yang paling membutuhkan pertolongan segera untuk keselamatan jiwanya. Pihak Kantor Palang Merah Indonesia(PMI) Medan memberikan sebuah reward atau penghargaan dengan tujuan meningkatkan kinerja proses pendistribusian darah yang bertugas, dan untuk menentukan prioritas pendistribusian darah maka dibutuhkan alternatif dan kriteria yang akan menjadi suatu acuan didalam proses pemilihan. Sistem Pendukung Keputusan merupakan salah satu cara yang bisa digunakan dalam proses prioritas pendistribusian darah. Dalam penelitian ini, penulis menggunakan metode The Extended Promethee II (Exprome II) untuk mencari nilai bobot dari kriteria, dan untuk mencari nilai akhir ataupun untuk mencari nilai perankingan Prioritas pendistribusian darah. Dengan demikian Sistem Pendukung Keputusan sangat dibutuhkan agar dapat membantu pihak Palang Merah Indonesia(PMI) Medan untuk menentukan Prioritas pendistribusian darah.

Kata Kunci: Sistem Pendukung Keputusan, The Extended Promthee II, Pemilihan Prioritas pendistribusian Darah

Abstract

PMI (Indonesian Red Cross) is a national association organization in Indonesia engaged in the field of social humanity. In carrying out its duties PMI does not make a difference but rather prioritizes victims who most need immediate help for the safety of their souls. The Indonesian Red Cross Office (PMI) Medan provides a reward or award with the aim of improving the performance of the blood distribution process in charge, and to determine the priority of blood distribution, alternatives and criteria are needed to become a reference in the selection process. Decision Support System is one way that can be used in the priority process of blood distribution. In this study, the authors used the Extended Promethee II (Exprome II) method to find the weight value of the criteria, and to find the final value or to find the priority value of blood distribution. Thus a Decision Support System is needed in order to help the Indonesian Red Cross (PMI) Medan to determine the priority of blood distribution.
\end{abstract}

Keywords: Decision Support System, The Extended Promthee II, Priority Selection of Blood distribution

\section{PENDAhUlUAN}

Pada saat ini distribusi darah khususnya di Indonesia sendiri memiliki masalah yang cukup besar dan perlu ditangani dengan sangat serius. Untuk menentukan prioritas distribusi darah, dibutuhkan kriteria-kriteria untuk setiap alternatif yang akan dipilih. Selama ini Kantor Palang Merah Indonesia (PMI) sudah melakukan pemilihan terhadap prioritas darah terhadap rumah sakit yang membutuhkan, biaya operasional dan jarak tempuh merupakan masalah yang sedang dihadapi ketika mendistribusikan darah sehingga informasi yang dihasilkan bersifat transparan dan pemilihan pendistribusian tidak dapat dilakukan dengan adil.

Berdasarkan Penelitian terdahulu yang dilakukan Moh Royandi Azkia (2018) dengan judul Perencanaan Distribusi Kantong Darah Menggunakan Sistem Pendukung Keputusan Dengan menerapkan Metode TOPSIS dan Fuzzy Sugeno, dilakukan terlebih dahulu perbandingan antara satu kriteria dengan kriteria lainnya yang telah ditetapkan hasil penelitian yaitu akurasi yang dihasilkan oleh sistem pendukung keputusan memperoleh akurasi yang sangat optimal dan memiliki ketepan yang sangat besar dalam melihat rangking bak darah. Pada tahun 2017, Ageng Puspita Pratidina melakukan penelitian dengan judul Sistem Pendukung Keputusan Kelayakan Peserta Untuk mengikuti Proses Pelelangan Barang dan Jasa Pada Pegadaian.

Tujuan penelitian ini adalah Untuk mengetahui proses yang dibutuhkan Palang Merah Indonesia dalam menentukan prioritas pendistribusian darah, Untuk menerapkan metode The Extended Promethee II (EXPROM II) dalam penentuan prioritas pendistribusian darah, serta merancang aplikasi sistem pendukung keputusan dalam penentuan prioritas pendistribusian darah dengan menggunakan bahasa pemograman.Manfaat penelitian ini adalah membantu Palang Merah Indonesia untuk menghasilkan keputusan yang efektif dalam penentuan prioritas pendistribusian darah, mengurangi kecucurangan yang terjadi serta mengkasilkan alternatif sistem yang dapat diusulkan.

\section{TEORITIS}

\subsection{Sistem Pendukung Keputusan}


Sebuah sistem yang yang mampu memberikan kemampuan pemecahan masalah terhadap suatu masalah dengan menggunakan beberapa alternatif dan juga kriteria untuk mendapatkan hasil akhir yang terbaik.

\subsection{The Extended Promethe II}

Metode The Extended Promethee II (EXPROM II) merupakan metode dengan hasil keputusan atas fungsi preferensi dengan masalah melalui pendekatan perangkingan atau merupakan analisis multikriteria, membandingkan alternatif yang satu dengan alternatif yang lainnya dan menghitung selisih yang dimiliki oleh data berpasangan sehingga menghasilkan keluaran berupa nilai alteratif perangkingan berdasarkan nilai tertinggi, sehingga penggunaanya lebih mudah memperoleh hasil perangkingan yang lebih baik lagi.

Langkah-langkah dalam penyelesaian Sistem Pendukung Keputusan (SPK) dengan metode EXPROM II sebagai berikut :

1. Membuat Matriks Keputusan.

Matriks keputusan yaitu matriks yang terdiri dari nilai alternatif $i$ untuk setiap kriteria $j$.

2. Normalisai Matriks Keputusan

Untuk kriteria benefit:

$r_{i j} \frac{\left[X_{i j}-\min \left(X_{i j}\right)\right]}{\left[\max \left(X_{i j}\right)-\min \left(X_{i j}\right)\right]}(\mathrm{i}=1,2, \ldots, \mathrm{m} ; \mathrm{j}=1,2, . . \mathrm{n})$

Untuk kriteria cost:

$r_{i j} \frac{\left[\max \left(X_{i j}\right)-X_{i j}\right]}{\left[\max \left(X_{i j}\right)-\min \left(X_{i j}\right)\right]}$

dimana: $r i j=$ matriks ternormalisasi

$$
\begin{aligned}
& i=\text { alternatif } \\
& j=\text { kriteria }
\end{aligned}
$$

3. Penentuan Fungsi Preferensi $P_{j}\left(i, i^{\prime}\right)$.

Persamaan Fungsi Preferensi $P_{j}\left(i, i^{\prime}\right)$ diberikan dibawah ini

$P_{i j}\left(i, i^{\prime}\right)=0$ if $r_{i j} \leq r_{i \prime j}$

$P_{i j}\left(i, i^{\prime}\right)=\left(r_{i j}-r_{i, j}\right)$ if $r_{i j}>r_{i \prime j}$

Dimana: $P_{i j}=$ Fungsi Preferensi

$$
\begin{aligned}
& i=\text { alternatif } \\
& i^{\prime}=\text { alternatif yang akan dipasangkan }
\end{aligned}
$$

4. Menghitung Nilai Weak Preference (WP)

Menghitung Indeks Prefrensi yang lemah dan mempertimbangkan kriteria dengan bobot yang berbeda untuk setiap kriteria persamaannya sebagai berikut:

$\mathrm{WP}\left(i, i^{\prime}\right)=\left[\sum_{j=1}^{n} W_{j} \times P_{j}(i, i)\right] \sum_{j=1}^{n} W_{j}$

Dimana: WP = Weak Preference

$\mathrm{n}=$ jumlah kriteria

$W_{j}=$ bobot kriteria $j$

5. Menghitung Nilai $S P_{j}\left(i, i^{\prime}\right)$

Menentukan nilai fungsi preferensi yang kuat $S P_{j}\left(i, i^{\prime}\right)$ sebagai berikut:

$S P_{j}\left(i, i^{\prime}\right)=\left[\max \left(0, d_{j}-L_{j}\right] /\left[d m_{j}-L_{j}\right]\right.$

dimana: $\mathrm{SP} j=$ Strict Preference kriteria $j$

$$
\begin{gathered}
\mathrm{dj}=\text { rij-ri'j } \\
d m_{j}=1 \\
L_{j}=0
\end{gathered}
$$

6. Menghitung Nilai Strict Preference (SP)

$S P_{j}\left(i, i^{\prime}\right)=\left[\sum_{j=1}^{n} W_{j} \mathrm{xS} P_{j}(i, i)\right] \sum_{j=1}^{n} W_{j}$

Dimana: $\mathrm{SP}=$ Weak Preference

$\mathrm{n}=$ jumlah kriteria

$W_{j}=$ bobot kriteria $j$

7. Menghitung Nilai Total Preference atau TP ( $\left.i, i^{\prime}\right)$

$\mathrm{TP}\left(i, i^{\prime}\right)=\operatorname{Min}\left[1, \mathrm{WP}\left(i, i^{\prime}\right)+\mathrm{SP}\left(i, i^{\prime}\right)\right]$

8. Menghitung aliran yang keluar (Entering) dan aliran yang masuk (Leaving Flow) menggunakann persamaan: Untuk arah keluar (positif) pada alternatif $i$ : 


$$
\varphi^{+}(\mathrm{i})=\frac{1}{m-1} \sum_{j=1}^{n} \mathrm{TP}\left(i, i^{\prime}\right)\left(i \neq i^{\prime}\right)
$$

Untuk arah masuk (negatif) pada alternatif $i$ :

$$
\varphi^{-}(\mathrm{i})=\frac{1}{m-1} \sum_{j=1}^{n} \mathrm{TP}\left(i, i^{\prime}\right)\left(i \neq i^{\prime}\right)
$$

dimana: $i=$ alternatif

$$
\begin{aligned}
i & =\text { alternatif yang dipasangkan } \\
\mathrm{m} & =\text { jumlah alternatif } \\
\mathrm{n} & =\text { jumlah kriteria }
\end{aligned}
$$

Aliran keluar berarti berapa banyak alternatif yang mendominasikan alternatif lainnya, sedangkan aliran keluar yaitu berapa banyak alternatif didomikasikan oleh alternatif yang lainnya.

9. Menghitung Net Flow

Dari perhitungan perangkingan $\varphi(\mathrm{i})$ untuk alternatif lain: $\varphi(\mathrm{i})=\varphi^{+}(\mathrm{i})-\varphi^{-}(\mathrm{i})$

10. Yang terakhir adalah penentuan rangking, metode EXPROM II ini merupakan pengambilan dari Nilai yang terbaik atau alternatif terbaik adalah alternatif yang memiliki nilai $\varphi(\mathrm{i})$ tertinggi.

\subsection{Prioritas}

Prioritas adalah sesuatu yang didahulukan untuk dikerjakan dan menyisahkan waktu yang cukup untuk menegrjakan yang lainnya.

\subsection{Pendistribusian Darah}

Pendistribusian darah adalah kegiatan pemasaran yang berusaha memperlancar serta mempermudah penyampaian darah kerumah sakit-rumah sakit yang membutuhkan darah tersebut.

\section{ANALIASA DAN PEMBAHASAN}

Dalam proses pemilihan prioritas pendistribusian darah ini, pemilihan yang dilakukan sangat ketat karena tahapan proses yang dilakukan harus disesuaikan dengan setiap kriteria-kriteria dari alternatif yang ada. Sistem yang sedang berjalan pada saat ini dalam proses menentukan prioritas pendistribusian darah dilakukan dengan hanya berdasarkan kriteria-kriteria tertentu dan dimana informasi dalam proses pemilihan prioritas pendistribusian darah masih kurang transparan sehingga hasil yang ditetapkan kurang maksimal dan pemilihan yang dilakukan dapat berjalan dengan adil. Agar proses pemilihan prioritas pendistribusian darah dapat dilakukan dengan lebih efektif dan efisien, maka diperlukan sistem pendukung keputusan yang dapat membantu mempermudah dalam melakukan pemilihan Prioritas Pendistribusian Darah di Palang Merah Indonesia (PMI) Medan.

Alternatif-alternatif pendistribusian darah yang akan di prioritaskan yaitu antara lain berikut ini:

Tabel 1. Tabel Alternatif

\begin{tabular}{ll}
\hline Kode & Nama Alternatif \\
\hline A1 & RSU Adama Malik \\
A2 & RS Colombia Asia \\
A3 & RS Herna Medan \\
A4 & RSU Haji \\
A5 & RSU Imelda \\
A6 & RSU Murni Teguh \\
A7 & RSU Sundari \\
A8 & RSU Bina Kasih \\
A9 & RSU Royal Prima \\
A10 & RSU Dr.Pringadi Medan \\
\hline
\end{tabular}

Berikut dibawah ini merupakan tabel Kriteria

Tabel 2. Tabel Kriteria

\begin{tabular}{lll}
\hline Kode & Nama & Bobot \\
\hline C1 & Ketersedian Darah (PD) & $25 \%$ Benefit \\
C2 & Permintaan Darah (PD) & $35 \%$ Cost \\
C3 & Banyak Pemakaian Darah (BPD) & $25 \%$ Cost \\
C4 & Jarak Tempuh (JT) & $15 \%$ Cost \\
\hline
\end{tabular}


Nilai alternatif untuk setiap kriteria terlihat seperti tabel berikut ini:

Tabel 3. Tabel Nilai Untuk Setiap Kriteria

\begin{tabular}{|c|c|c|c|c|}
\hline \multirow[t]{2}{*}{ Alternatif } & \multicolumn{4}{|l|}{ Kriteria } \\
\hline & KD & PD & BPD & JP \\
\hline RSU Adam Malik & Ada & $>1871-2680$ Per Kantong & $>1871-2550$ Per Kantong & Sangat \\
\hline RS Colombia Asia & Tidak Ada & $\begin{array}{l}\text { Darah } \\
\text { >325-100 Per Kantong } \\
\text { Darah }\end{array}$ & $\begin{array}{l}\text { Darah } \\
\text { >330 Per Kantong Darah }\end{array}$ & $\begin{array}{l}\text { Jauh } \\
\text { Cukup } \\
\text { Jauh }\end{array}$ \\
\hline RS Herna Medan & Kurang Cukup & $<100$ Per Kantong Darah & > 94 Per Kantong Darah & Dekat \\
\hline RSU Haji & Ada & >10 Per Kantong Darah & $<5$ Per Kantong Darah & $\begin{array}{l}\text { Sangat } \\
\text { Jauh }\end{array}$ \\
\hline RSU Imelda & Tidak Ada & $<10$ Per Kantong Darah & $>0$ Per Kantong Darah & $\begin{array}{l}\text { Cukup } \\
\text { Jauh }\end{array}$ \\
\hline RSU Murni Teguh & Kurang Cukup & $\begin{array}{l}>1871-2680 \text { Per Kantong } \\
\text { Darah }\end{array}$ & $\begin{array}{l}>1871-2550 \text { Per Kantong } \\
\text { Darah }\end{array}$ & Dekat \\
\hline RSU Sundari & Ada & $\begin{array}{l}>325-100 \text { Per Kantong } \\
\text { Darah }\end{array}$ & >330 Per Kantong Darah & $\begin{array}{l}\text { Sangat } \\
\text { Jauh }\end{array}$ \\
\hline RSU Bina Kasih & Tidak Ada & $<100$ Per Kantong Darah & > 94 Per Kantong Darah & $\begin{array}{l}\text { Cukup } \\
\text { Jauh }\end{array}$ \\
\hline RSU Royal Prima & Kurang Cukup & $>10$ Per Kantong Darah & $<5$ Per Kantong Darah & Dekat \\
\hline $\begin{array}{l}\text { RSU Dr.Pringadi } \\
\text { Medan }\end{array}$ & Ada & $<10$ Per Kantong Darah & $>0$ Per Kantong Darah & $\begin{array}{l}\text { Sangat } \\
\text { Jauh }\end{array}$ \\
\hline
\end{tabular}

Langkah-langkah dalam penyelesaian Sistem Pendukung Keputusan (SPK) dengan metode EXPROM II sebagai berikut :

1. Membuat Matriks Keputusan

2. Normalisasi Matriks Keputusan

$\left[\begin{array}{cccc}80 & 100 & 80 & 5 \\ 80 & 80 & 80 & 3 \\ 60 & 60 & 80 & 3 \\ 80 & 80 & 80 & 3 \\ 60 & 80 & 60 & 2 \\ 40 & 60 & 60 & 1 \\ 100 & 40 & 60 & 3 \\ 20 & 40 & 20 & 3 \\ 60 & 20 & 80 & 2 \\ 60 & 100 & 20 & 1\end{array}\right]$

Berikut penjabaran proses perhitungan normalisasi matriks keputusan:

C1: Ketersediaan Darah (KD) $\square$ Benefit

$\mathrm{rij}=[\mathrm{xij}-\min (\mathrm{xij})] /[\max (\mathrm{xij})-\min (\mathrm{xij})]$

dimana: $i=$ alternatif

$$
\begin{aligned}
& R_{11}=\frac{[80-20]}{[100-20]}=0.75 \\
& R_{21}=\frac{[80-20]}{[100-20]}=0.75 \\
& R_{31}=\frac{[80-20]}{[100-20]}=0.75 \\
& R_{41}=\frac{[60-20]}{[100-20]}=0.5 \\
& R_{51}=\frac{[60-20]}{[100-20]}=0.5
\end{aligned}
$$

Setelah proses perhitungan normalisasi matrik penentuan prioritas pendistribusian darah sampai di r109 maka dapat diperoleh hasil normalisasi matriks berikut ini: 
3. Penentuan Fungsi Preferensi $P_{j}\left(i, i^{\prime}\right)$.

$\left[\begin{array}{cccc}1 & 0.75 & 0.75 & 0 \\ 0.75 & 0.75 & 0.75 & 0.5 \\ 0.5 & 0.75 & 0.75 & 0.5 \\ 0.75 & 0.5 & 0.75 & 0.5 \\ 0.75 & 0.5 & 0.75 & 0.75 \\ 0.5 & 0.25 & 0.5 & 1 \\ 0.25 & 1 & 0.5 & 0.5 \\ 0 & 0 & 0 & 0.5 \\ 1 & 0.5 & 0.75 & 0.75 \\ 0.75 & 0.5 & 0 & 1\end{array}\right]$

Nilai yang di peroleh dari preferensi ini berupa nilai alternatif yang akan dipasangkan berdasarkan perbandingan selisih.

C1 : Ketersediaan Darah (KD)

$\mathrm{r} 11 \leq \mathrm{r} 21, \mathrm{P} 1(1,2)=0$

$\mathrm{r} 11>\mathrm{r} 31, \mathrm{P} 1(1,3)=0$

$\mathrm{r} 11 \leq \mathrm{r} 41, \mathrm{P} l(1,4)=0.75-0,5=0.25$

$\mathrm{r} 11 \leq \mathrm{r} 51, \mathrm{P} 1(1,5)=0.75-0,5=0.25$

Tabel 4. Nilai Preferensi

\begin{tabular}{lllll}
\hline Alternatif & PD & PD & PD & JT \\
\hline $\operatorname{Pj}(1,2)$ & 0.25 & 0 & 0 & 0 \\
$\operatorname{Pj}(1,3)$ & 0.5 & 0 & 0 & 0 \\
$\operatorname{Pj}(1,4)$ & 0.25 & 0.25 & 0 & 0 \\
$\operatorname{Pj}(1,5)$ & 0.25 & 0.25 & 0 & 0 \\
$\operatorname{Pj}(1,6)$ & 0.25 & 0,5 & 0,25 & 0 \\
$\operatorname{Pj}(1,7)$ & 0.75 & 0,75 & 0,25 & 0 \\
$\operatorname{Pj}(1,8)$ & 1 & 0 & 0,75 & 0 \\
$\operatorname{Pj}(1,9)$ & 0 & 0 & 0 & 0 \\
$\operatorname{Pj}(1,10)$ & 0.25 & 0.25 & 0,75 & 0 \\
\hline
\end{tabular}

4. Menghitung Nilai Weak Preference (WP)

$$
\begin{gathered}
{\left[\sum_{j=1}^{n} W_{j} \mathrm{x} P_{j}(i, i)\right] \sum_{j=1}^{n} W_{j}} \\
\text { Dimana: } \begin{array}{l}
\text { WP }=\text { Weak Preference } \\
\mathrm{n}=\text { jumlah kriteria } \\
W_{j}=\text { bobot kriteria } j
\end{array}
\end{gathered}
$$

5. Menghitung Nilai $S P_{j}\left(i, i^{\prime}\right)$

$S P_{j}\left(i, i^{\prime}\right)=\left[\max \left(0, d_{j}-L_{j}\right] /\left[d m_{j}-L_{j}\right]\right.$

dimana: $\operatorname{SP} j=$ Strict Preference kriteria $j$

$$
\begin{aligned}
& \mathrm{dj}=\text { rij-ri'j } \\
& d m_{j}=1 \\
& L_{j}=0
\end{aligned}
$$

6. Menghitung Nilai Strict Preference (SP)

$S P_{j}\left(i, i^{\prime}\right)=\left[\sum_{j=1}^{n} W_{j} \times S P_{j}(i, i)\right] \sum_{j=1}^{n} W_{j}$

Dimana: $\mathrm{SP}=$ Weak Preference

$$
\begin{aligned}
\mathrm{n} & =\text { jumlah kriteria } \\
W_{j} & =\text { bobot kriteria } j
\end{aligned}
$$

7. Menghitung Nilai $T P\left(i, i^{\prime}\right)$

$$
\mathrm{TP}\left(i, i^{\prime}\right)=\operatorname{Min}\left[1, \mathrm{WP}\left(i, i^{\prime}\right)+\mathrm{SP}\left(i, i^{\prime}\right)\right]
$$

Tabel 5. Nilai Total Preference TP $\left(i, i^{\prime}\right)$

\begin{tabular}{ll}
\hline Alternatif & Perhitungan \\
\hline $\operatorname{TP}(1,2)$ & Min[1,0+0] $=0$ \\
$\operatorname{TP}(1,3)$ & $\operatorname{Min}[1,0.2+0.2]=0.4$ \\
$\operatorname{TP}(1,4)$ & $\operatorname{Min}[1,0.4+0.4]=0.8$ \\
$\operatorname{TP}(1,5)$ & $\operatorname{Min}[1,0.2+0.2]=0.4$
\end{tabular}




\begin{tabular}{ll}
$\operatorname{TP}(1,6)$ & $\operatorname{Min}[1,0.2+0.2]=0.4$ \\
$\operatorname{TP}(1,7)$ & $\operatorname{Min}[1,0.3+0.3]=0.6$ \\
$\operatorname{TP}(1,8)$ & $\operatorname{Min}[1,0.2+0.2]=0.4$ \\
$\operatorname{TP}(1,9)$ & $\operatorname{Min}[1,0.2+0.2]=0.4$ \\
$\operatorname{TP}(1,10)$ & $\operatorname{Min}[1,0.3+0.4]=0.7$ \\
\hline
\end{tabular}

8. Menghitung aliran yang keluar (Entering) dan aliran yang masuk (Leaving Flow) Untuk arah keluar (positif) pada alternatif $i$ :

$\varphi^{+}(\mathrm{i})=\frac{1}{m-1} \sum_{j=1}^{n} \mathrm{TP}\left(i, i^{\prime}\right)\left(i \neq i^{\prime}\right)$

Untuk arah masuk (negatif) pada alternatif $i$ :

$\varphi^{-}(\mathrm{i})=\frac{1}{m-1} \sum_{j=1}^{n} \operatorname{TP}\left(i, i^{\prime}\right)\left(i \neq i^{\prime}\right)$

9. Menghitung Net Flow $\varphi(i)=\varphi^{+}(\mathrm{i})-\varphi^{-}(\mathrm{i})$

10. Yang terakhir adalah penentuan rangking yang diproleh menggunakan metode Exprome II.

Tabel 6. Perangkinangan

\begin{tabular}{lllll}
\hline Alternatif & $(+)$ & $(-)$ & $\boldsymbol{\varphi}(\boldsymbol{i})$ & Peringkat \\
\hline RSU Adama Malik & 0.4044 & 0.4688 & $-0,0644$ & 9 \\
RS Colombia Asia & 0.6977 & 0,5022 & 0,1955 & 4 \\
RS Herna Medan & 0.4266 & 0,3466 & 0,08 & 10 \\
RSU Haji & 0.3777 & 0,64 & $-0,2623$ & 2 \\
RSU Imelda & 0.3777 & 0,5022 & -0.1245 & 5 \\
RSU Murni Teguh & 0.3777 & 0,4933 & -0.1156 & 6 \\
RSU Sundari & 0.3955 & 0,48 & $-0,0845$ & 7 \\
RSU Bina Kasih & 0.5866 & 0,4444 & 0,4444 & 1 \\
RSU Royal Prima & 0.5844 & 0,3688 & $-0,2156$ & 3 \\
RSU Dr.Pringadi Medan & 0.5444 & 0,4555 & $-0,0889$ & 8 \\
\hline
\end{tabular}

\section{KESIMPULAN}

Setelah melakukan analisa masalah, Pembahasan Masalah maka dapat ditarik kesimpulan sebagai berikut :

1. Proses pemilihan Prioritas Pendistribusian Darah dengan menggunakan metode The Extended Promethee II dapat menjadi salah satu pemecahan masalah dalam pemilihan Prioritas Pendistribusian Darah pada kantor Palang Merah Indonesia(PMI) Medan

2. Dengan menerapkan metode Exprome II untuk mencari niai pembobotan dan untuk mencari hasil perankingan.

3. Sistem yang digunakan untuk merancang sistem pendukung keputusan pemilihan Prioritas Pendistribusian Darah terbaik dengan menggunakan Visual Studio 2008.

\section{REFERENCES}

[1] Y. Silalahi and T. Zebua, "PENERAPAN THE EXTENDED PROMETHEE II ( EXPROM II ) UNTUK," vol. I, no. Exprom Ii, 2017.

[2] C. Paper, M. Aan, S. Budi, T. Zebua, A. Stiekom, S. Utara, S. Gienam, S. Budi, C. View, I. A. View, and T. Zebua, "PENERAPAN THE EXTENDED PROMETHEE II ( EXPROM II ) UNTUK PENENTUAN PRODUK," no. November, 2017.

[3] M. K. Kusrini, Konsep Dan Aplikasi Sistem Pendukung Keputusan. Yogyakarta: Andi, 2007.

[4] K. Umam, V. E. Sulastri, T. Andini, and D. U. Sutiksno, "Perancangan Sistem Pendukung Keputusan Penentuan Prioritas Produk Unggulan Daerah Menggunakan Metode VIKOR," vol. 5, no. 1, pp. 43-49, 2018.

[5] M. Rusman and R. D. Mudiastuti, "Perencanaan Optimasi Distribusi Darah di Kota Makassar,” no. 1, 2014.

[6] M. R. Azkia, "Perencanaan Distribusi Kantong Darah Menggunakan Sistem Pendukung Keputusan Dengan Algoritma TOPSIS dan Fuzzy Sugeno,” pp. 170-175, 2018.

[7] S. Pendukung, K. Pemilihan, K. Safitri, and F. T. Waruwu, "BERPRESTASI DENGAN MENGGUNAKAN METODE ANALYTICAL HIEARARCHY PROCESS ( Studi Kasus : PT . Capella Dinamik Nusantara Takengon ),” vol. 1, no. 1, pp. $17-21,2017$. 